\title{
The inpatient burden of abdominal and gynecological adhesiolysis in the US
}

\author{
Vanja Sikirica ${ }^{1}$, Bela Bapat ${ }^{2}$, Sean D Candrilli ${ }^{2}$, Keith L Davis ${ }^{2}$, Malcolm Wilson ${ }^{3}$ and Alan Johns ${ }^{4}$
}

\begin{abstract}
Background: Adhesions are fibrous bands of scar tissue, often a result of surgery, that form between internal organs and tissues, joining them together abnormally. Postoperative adhesions frequently occur following abdominal surgery, and are associated with a large economic burden. This study examines the inpatient burden of adhesiolysis in the United States (i.e., number and rate of events, cost, length of stay [LOS]).

Methods: Hospital discharge data for patients with primary and secondary adhesiolysis were analyzed using the 2005 Healthcare Cost and Utilization Project's Nationwide Inpatient Sample. Procedures were aggregated by body system.

Results: We identified 351,777 adhesiolysis-related hospitalizations: $23.2 \%$ for primary and $76.8 \%$ for secondary adhesiolysis. The average LOS was 7.8 days for primary adhesiolysis. We found that 967,332 days of care were attributed to adhesiolysis-related procedures, with inpatient expenditures totaling $\$ 2.3$ billion ( $\$ 1.4$ billion for primary adhesiolysis; $\$ 926$ million for secondary adhesiolysis). Hospitalizations for adhesiolysis increased steadily by age and were higher for women. Of secondary adhesiolysis procedures, $46.3 \%$ involved the female reproductive tract, resulting in 57,005 additional days of care and \$220 million in attributable costs.
\end{abstract}

Conclusions: Adhesiolysis remain an important surgical problem in the United States. Hospitalization for this condition leads to high direct surgical costs, which should be of interest to providers and payers.

Keywords: Adhesions, adhesiolysis, abdominal, gynecological, burden of illness, hospitalizations

\section{Background}

Adhesions are fibrous bands of scar tissue, often result of surgery, that form between internal organs and tissues, joining them together abnormally [1]. Postoperative adhesions frequently occur following abdominal surgery and are a leading cause of intestinal obstruction. It has been estimated that more than $90 \%$ of patients who undergo abdominal operations will develop postoperative adhesions [2].

The most severe complication of postoperative adhesions is small bowel obstruction (SBO), which has a $10 \%$ risk of mortality [3,4]. Recent research has demonstrated that readmission episodes averaged 2.7 per patient for SBO or nonspecific abdominal pain (when adhesions were considered likely). Inpatient readmissions accounted for $87 \%$ of episodes; $47 \%$ of those required repeat surgery [5]. Additionally, in the large retrospective study Surgical

\footnotetext{
* Correspondence: scandrilli@rti.org

${ }^{2}$ RTI Health Solutions, 200 Park Offices, Research Triangle Park, NC 27709 USA Full list of author information is available at the end of the article
}

and Clinical Adhesions Research, surgical procedures performed on the bowel or the female reproductive system were associated with an increased chance of adhesion development, termed adhesiolysis [6-8]. Ray and colleagues found that $47 \%$ of adhesiolysis-related inpatient hospitalizations were for procedures involving the female reproductive tract [2]. Postoperative adhesiolysisrelated SBO occurred in $2.8 \%$ of patients undergoing hysterectomy for benign conditions and in $5 \%$ of those undergoing radical hysterectomy $[4,9]$.

A number of studies have shown that the economic burden of adhesiolysis is significant $[2,5,10]$. It was estimated that adhesiolysis procedures resulted in 303,836 hospitalizations, 846,415 days of inpatient care, and nearly $\$ 1.3$ billion in health care expenditures in the United States (US) in 1994 [2]. This cost has decreased when compared with similar data from 1988,[10] due in part to laparoscopic surgery. Despite the decrease in costs associated with laparoscopic surgery, increased use of such techniques did not lead to a decreased rate of overall hospitalizations [2].
Ciomed Central

() 2011 Sikirica et al; licensee BioMed Central Ltd. This is an Open Access article distributed under the terms of the Creative Commons Attribution License (http://creativecommons.org/licenses/by/2.0), which permits unrestricted use, distribution, and reproduction in any medium, provided the original work is properly cited. 
Utilizing more recent data, we estimated the current burden of inpatient treatment of adhesiolysis in the US. This study examined the number and rate of adhesiolysis-related hospitalizations, days of care attributable to adhesiolysis, and length of stay (LOS) for adhesiolysisrelated hospitalizations, with primary and secondary procedures considered separately. Additionally, we assessed total inpatient costs attributable to adhesiolysis.

\section{Methods}

\section{Data Source}

Data were taken from the 2005 Healthcare Cost and Utilization Project's (HCUP) Nationwide Inpatient Sample (NIS)[11]. The NIS is the largest all-payer inpatient care database in the US and contains data from approximately 8 million hospital stays in 2005 . The database also contains clinical and resource use information, including patient demographics, International Classification of Diseases, 9th Revision, Clinical Modification (ICD-9-CM) diagnosis and procedure codes, diagnosisrelated group (DRG) codes, LOS, charges, discharge status, payer source, and hospital-specific characteristics. Using the survey design elements provided with the NIS, data can be weighted to produce nationally representative estimates [12]. All financial information in the NIS database is presented as charges rather than costs. To convert hospital charges to costs, facility-specific cost-to-charge ratios were used. Finally, the medical care component of the Consumer Price Index was applied to inflate all financial data to 2007 US dollars [13].

RTI International's Institutional Review Board determined that this study met all criteria for exemption.

\section{Study Sample}

From the NIS, all hospitalizations containing a DRG code of peritoneal adhesiolysis with or without complications (i.e., DRG 150, 151) were defined as primary adhesiolysis-related hospitalizations. Hospitalizations containing a primary or nonprimary ICD-9-CM procedure code for adhesiolysis, but without DRG 150 or 151, were defined as secondary adhesiolysis-related hospitalizations (Table 1). Hospitalizations related to secondary adhesiolysis were stratified by body system, using the following DRG coding:

(1) Digestive system (i.e., DRG 148, 149, 154, or 468),

(2) Hepatobiliary system (i.e., DRG 197, 493, or 494),

(3) Female reproductive system (i.e., DRG 358, 359, 361 , or 365),

(4) Pregnancy with evidence of Cesarean section (i.e., DRG 370, 371, or 378).

\section{Study Measures}

Study measures included the number of inpatient hospitalizations involving adhesiolysis, adhesiolysis-related hospitalization rates, days of care, and costs attributable to adhesiolysis.

Hospitalization rates per 100,000 persons were assessed using the US Census Bureau's 2005 total US civilian population projection. The total days of care attributable to adhesiolysis were estimated using methods presented by Ray and colleagues that then were adapted for the HCUP NIS [2]. When DRG 150 or 151 (i.e., primary adhesiolysis) was the primary reason for admission, the attributed LOS was simply the mean LOS for this group. For records without a DRG of 150 or 151, excess days attributed to adhesiolysis were calculated as the difference between the mean LOS for those same procedures with adhesiolysis and those procedures without adhesiolysis within each DRG. The total number of adhesiolysis-related days then was estimated as the product of the attributed LOS for the group and the number of adhesiolysis-related hospitalizations within the group.

This study utilized the methodology from Ray and colleagues to estimate the per-day cost attributable to adhesiolysis [2]. Cost per day was estimated by dividing the total cost of adhesiolysis-related hospitalizations divided by the total number of adhesiolysis-related inpatient days. The total inpatient expenditures attributable to adhesiolysis were estimated by multiplying the estimated cost per day attributable to adhesiolysis by the number of days attributed to adhesiolysis.

Average expenditures for surgeon's services were estimated using the Resource-Based Relative Value Scale (RBRVS). The RBRVS value was estimated for Current Procedural Terminology codes related to adhesiolysis (Table 2) and then multiplied by a fixed conversion factor to determine the average surgeon expenditures for each specific procedure. These figures then were inflated to 2007 dollars using the medical care component of the Consumer Price Index.

Total inpatient costs attributable to adhesiolysis consisted of inpatient costs and costs for the surgeon's services. Estimates were made separately for primary and secondary adhesiolysis. These also were examined by body system and then aggregated to estimate a total cost. Additionally, inpatient expenditures were summarized to compare Cesarean section deliveries with and without adhesiolysis.

\section{Statistical Analyses}

Descriptive analyses were conducted to display the mean, standard deviation, median, and range of continuous variables, as well as the frequency distribution of categorical variables. All data management and analyses 


\begin{tabular}{ll}
\hline ICD-9-CM Procedure Code & Brief Description \\
\hline Nongynecologic & \\
54.5 & Lysis of peritoneal adhesions \\
54.59 & Laparoscopic lysis of peritoneal adhesions \\
56.81 & Other lysis of peritoneal adhesions \\
57.12 & Lysis of intraluminal adhesions of ureter \\
57.41 & Lysis of intraluminal adhesions with incision into bladder \\
58.5 & Transurethral lysis of intraluminal adhesions \\
59.01 & Release of urethral structure \\
59.02 & Ureterolysis with freeing or repositioning of ureter for retroperitoneal fibrosis \\
59.03 & Other lysis of perirenal or periureteral adhesions \\
59.11 & Laparoscopic lysis of perirenal or periureteral adhesions \\
59.12 & Other lysis of perivesical adhesions \\
68.21 & Laparoscopic lysis of perivesical adhesions \\
& Division of endometrial synechiae \\
65.8 & \\
65.81 & Lysis of adhesions of ovary and fallopian tube \\
65.89 & Laparoscopic lysis of adhesions of ovary and fallopian tube \\
70.13 & Other lysis of adhesions of ovary and fallopian tube \\
71.01 & Lysis of intraluminal adhesions of vagina \\
\hline
\end{tabular}

ICD-9-CM = International Classification of Diseases, 9th Revision, Clinical Modification.

were conducted with SAS and SUDAAN statistical software packages $[14,15]$.

\section{Results and Discussion}

Table 3 illustrates that there were 351,777 adhesiolysisrelated hospitalizations in the US in 2005, representing 119 adhesiolysis hospitalizations per 100,000 persons. There were 898 adhesiolysis hospitalizations per 100,000 hospitalizations and 3,549 per 100,000 surgical hospitalizations of any kind (3.5\%). Primary adhesiolysis (i.e., DRG 150 or 151) was found in $23.2 \%$ of these hospitalizations, while the remaining $76.8 \%$ were classified as secondary adhesiolysis (i.e., evidence of the procedure but with a DRG other than 150 or 151).
Table 4 presents background characteristics for the study sample. For primary adhesiolysis, the number of hospitalizations increased steadily by age; for secondary adhesiolysis, the number increased for most age categories. The lowest rate was in patients who were younger than 25 years (5.2 per 100,000 persons for primary adhesiolysis; 13.8 per 100,000 persons for secondary adhesiolysis), and the highest rate was in patients who were older than 65 years (88.4 per 100,000 persons for primary adhesiolysis; 176.7 per 100,000 persons for secondary adhesiolysis). Women had a higher hospitalization rate than men (34.9 vs. 19.7 per 100,000 persons for primary adhesiolysis; 153.1 vs. 13.4 per 100,000 persons for secondary adhesiolysis). Among primary adhesiolysis

Table 2 Description of Procedure (CPT) Codes Used to Identify Adhesiolysis-Related Surgical Procedures to Estimate Expenditures for Surgeons' Services ${ }^{a}$

\begin{tabular}{cl}
\hline CPT Code & Brief Description \\
\hline 44005 & Enterolysis (freeing of intestinal adhesion) \\
50715 & Ureterolysis, with or without repositioning of ureter for retroperitoneal fibrosis \\
50722 & Ureterolysis for ovarian vein syndrome \\
50725 & Ureterolysis for retrocaval ureter, with reanastomosis of upper urinary tract or vena cava \\
58660 & Laparoscopy, surgical; with lysis of adhesions (salpingolysis, ovariolysis) (separate) \\
58559 & Hysteroscopy with lysis of intrauterine adhesions (any method) \\
56441 & Lysis of labial adhesions \\
58740 & Lysis of adhesions (salpingolysis, ovariolysis) \\
\hline
\end{tabular}

CPT $=$ Current Procedural Terminology.

a CPT codes 56304 and 58985 were replaced by code 58660, and CPT code 57451 was retired. 
Table 3 Rate of Adhesiolysis-Related Hospitalizations

\begin{tabular}{|c|c|c|c|c|}
\hline Characteristic & $\begin{array}{c}\text { Estimated } \\
\text { Hospitalizations }\end{array}$ & $\begin{array}{c}\text { Rate of Hospitalizations per } \\
100,000 \text { in the US } \\
\text { Population }^{\mathrm{a}}\end{array}$ & $\begin{array}{c}\text { Rate of Hospitalizations per } \\
100,000 \text { Hospitalized } \\
\text { Persons }^{\mathrm{b}}\end{array}$ & $\begin{array}{c}\text { Rate of Hospitalizations per } 100,000 \\
\text { Hospitalized Persons for Surgical } \\
\text { Intervention }\end{array}$ \\
\hline Total number & 351,777 & 118.64 & 898.22 & $3,549.04$ \\
\hline $\begin{array}{l}\text { Adhesiolysis, } \\
\text { primary } \\
\text { procedure }\end{array}$ & 81,532 & 27.50 & 208.18 & 822.57 \\
\hline $\begin{array}{l}\text { Adhesiolysis, } \\
\text { secondary } \\
\text { procedure }\end{array}$ & 270,245 & 91.14 & 690.04 & $2,726.47$ \\
\hline
\end{tabular}

hospitalizations, almost half (48\%) of the patients were admitted via the emergency department, whereas only $20.5 \%$ of the secondary adhesiolysis hospitalizations were via the emergency department. Primary adhesiolysisrelated hospitalizations were evenly distributed between private insurance and governmental coverage, i.e., Medicaid and Medicare (44\% and $48 \%$, respectively), whereas more than half $(56 \%)$ of the patients with secondary adhesiolysis hospitalizations had private insurance and $37.4 \%$ had government-sponsored health care coverage.

A total of 967,332 inpatient days of care were attributed to primary and secondary adhesiolysis (Table 5). There were 81,532 hospitalizations and an average LOS of 7.8 days per stay, totaling 632,688 inpatient days of care for primary adhesiolysis. An estimated 334,644 days of care were attributed to secondary adhesiolysis. For hospitalizations in which adhesiolysis was a secondary procedure, we compared the LOS between adhesiolysis and nonadhesiolysis procedures to estimate the LOS attributable to adhesiolysis by each DRG. The majority of DRGs showed an increase in LOS for adhesiolysis hospitalizations versus nonadhesiolysis hospitalizations. On average, hospitalizations related to secondary adhesiolysis resulted in an additional 1.24 hospitalized days compared with nonadhesiolysis-related hospitalizations.

The difference in mean LOS was greatest for extensive operation room procedures unrelated to principal diagnosis (i.e., DRG 468), with 4.9 days attributable to adhesiolysis. For stomach, esophageal, and duodenal procedures with complications of comorbid conditions (i.e., DRG 154), 4.6 days were attributable to adhesiolysis. Almost half $(46.3 \%)$ of all secondary adhesiolysis procedures $(125,069)$ were female reproductive tract related, resulting in 57,005 days of care. Thus, 0.46 day of additional stay were attributable to adhesiolysis. The longest LOS for female reproductive system procedures was for DRG 358 (uterine and adnexa procedures for nonmalignancy), which resulted in an additional day of inpatient stay ( 0.90 day).
Table 6 shows that total inpatient expenditures for adhesiolysis-related hospitalizations were $\$ 2.25$ billion: of this amount, primary adhesiolysis-related hospitalizations accounted for $\$ 1.35$ billion and secondary adhesiolysis-related hospitalizations accounted for $\$ 902$ million. Of the total secondary adhesiolysis expenditures, $\$ 622$ million (69\%) were related to procedures for the digestive system and $\$ 220$ million (24.3\%) were related to procedures for the female reproductive system. Adhesiolysis related to the hepatobiliary system and pancreas and Cesarean sections accounted for $\$ 41$ million and $\$ 18$ million, respectively.

The rate of adhesiolysis-related hospitalizations in the US has remained fairly constant from 1998 to 2005: from 115.5 in 1988 [10] to 117.3 in 1994 [2] and ultimately 118.6 per 100,000 persons in 2005 . In these same time periods, the average LOS for primary adhesiolysisrelated hospitalizations has steadily decreased from 11.2 days to 9.7 days and 7.8 days, respectively. The costs for such hospitalizations, when inflated to reflect 2007 dollars, indicated an increase of $\$ 112$ million between 1988 and 2005, despite the 3.4-day (or 30\%) decrease in LOS-this represented a $5 \%$ increase in medical care costs. This increase suggested that costs of treating adhesiolysis have increased substantially.

Primary adhesiolysis contributed $23 \%$ of all adhesiolysis procedures $(81,532)$ but represented more than half of the total cost burden ( $\$ 1.3$ billion). Secondary adhesiolysis was substantially higher in volume, representing $77 \%$ of procedures $(270,245)$ but less half of the total cost burden (\$902 million). The greatest number of procedures was to the female reproductive tract $(125,069)$ while procedures to the digestive tract yielded the highest overall costs ( $\$ 622$ million).

Potentially mitigating this growth in the cost of adhesiolysis may be the continuing trend in the US toward minimally invasive and laparoscopic approaches, which may lessen the occurrence of postoperative adhesions [2]. Although laparoscopy reduces surgical trauma, the 
Table 4 Demographics and Other Patient- and Facility-Specific Characteristics of Interest Among Adhesiolysis-Related Hospitalizations (i.e., DRG 150 or 151) in the US in 2005

\begin{tabular}{|c|c|c|c|c|c|c|c|c|}
\hline \multirow[b]{2}{*}{ Characteristic } & \multicolumn{4}{|c|}{ Primary Procedure $(\mathrm{N}=81,532)$} & \multicolumn{4}{|c|}{ Secondary Procedure $(\mathrm{N}=\mathbf{2 7 0 , 2 4 5 )}$} \\
\hline & $\begin{array}{c}\text { Estimated } \\
\text { Hospitalizations }\end{array}$ & $\begin{array}{l}\text { Hospitalizations } \\
\text { per } 100,000 \\
\text { Population }\end{array}$ & $\begin{array}{c}\text { Rate of } \\
\text { Hospitalization } \\
\text { (All } \\
\text { Hospitalizations) }\end{array}$ & $\begin{array}{c}\text { Rate of } \\
\text { Hospitalization } \\
\text { (Surgical } \\
\text { Hospitalizations) }\end{array}$ & $\begin{array}{c}\text { Estimated } \\
\text { Hospitalizations }\end{array}$ & $\begin{array}{l}\text { Hospitalizations } \\
\text { per } 100,000 \\
\text { Persons }\end{array}$ & $\begin{array}{c}\text { Rate of } \\
\text { Hospitalization per } \\
100,000 \\
\text { Hospitalizations }\end{array}$ & $\begin{array}{l}\text { Rate of Hospitalization per } \\
\text { 100,000 Hospitalizations With } \\
\text { Surgical Procedure }\end{array}$ \\
\hline \multicolumn{9}{|l|}{ Age (years) } \\
\hline$<25$ & 5,297 & 5.15 & 56.19 & 456.49 & 14,212 & 13.82 & 150.75 & $1,224.79$ \\
\hline $25-34$ & 5,402 & 13.46 & 133.39 & 419.16 & 46,483 & 115.79 & $1,147.76$ & $3,606.77$ \\
\hline $35-44$ & 11,106 & 25.32 & 308.40 & 888.83 & 71,062 & 162.00 & $1,973.28$ & $5,687.19$ \\
\hline $45-54$ & 15,691 & 36.93 & 372.13 & $1,142.65$ & 52,732 & 124.11 & $1,250.61$ & $3,840.06$ \\
\hline $55-64$ & 14,324 & 47.19 & 322.36 & 970.96 & 27,644 & 91.07 & 622.13 & $1,873.86$ \\
\hline $65-74$ & 13,615 & 73.00 & 276.54 & 877.54 & 25,980 & 139.30 & 527.70 & $1,674.52$ \\
\hline$\geq 75$ & 16,034 & 88.40 & 189.72 & 893.19 & 32,047 & 176.69 & 379.20 & $1,785.20$ \\
\hline Missing & 64 & - & 125.96 & 352.54 & 86 & - & 169.25 & 473.72 \\
\hline \multicolumn{9}{|l|}{ Gender } \\
\hline Female & 52,579 & 34.93 & 228.80 & 874.57 & 230,422 & 153.07 & 1002.71 & $3,832.69$ \\
\hline Male & 28,696 & 19.66 & 178.76 & 746.39 & 39,614 & 13.36 & 246.77 & $1,030.37$ \\
\hline Missing & 256 & - & 195.29 & 463.40 & 208 & - & 158.68 & 376.51 \\
\hline \multicolumn{9}{|l|}{ Race/ethnicity } \\
\hline Caucasian & 47,344 & 19.90 & 241.10 & 889.04 & 134,079 & 56.36 & 682.79 & $2,517.78$ \\
\hline $\begin{array}{l}\text { African- } \\
\text { American }\end{array}$ & 6,325 & 16.69 & 186.29 & 920.21 & 31,153 & 82.19 & 917.53 & $4,532.39$ \\
\hline Other $^{\mathrm{a}}$ & 7,398 & 35.71 & 133.96 & 591.38 & 37,206 & 179.59 & 673.71 & $2,974.15$ \\
\hline Missing & 20,466 & - & 192.91 & 772.80 & 67,808 & - & 639.14 & $2,560.44$ \\
\hline \multicolumn{9}{|l|}{ Admission source } \\
\hline ER & 38,748 & - & 232.79 & $1,553.63$ & 55,369 & - & 332.64 & $2,220.06$ \\
\hline $\begin{array}{l}\text { Another } \\
\text { facility }\end{array}$ & 2,274 & - & 119.81 & 524.63 & 4,666 & - & 245.83 & $1,076.48$ \\
\hline Other $^{b}$ & 40,509 & - & 196.45 & 579.99 & 210,210 & - & $1,019.41$ & $3,009.70$ \\
\hline \multicolumn{9}{|l|}{ Discharge status } \\
\hline Routine & 63,979 & - & 220.83 & 865.62 & 225,752 & - & 779.22 & $3,054.37$ \\
\hline $\begin{array}{l}\text { Transfer to } \\
\text { short-term } \\
\text { hospital }\end{array}$ & 579 & - & 68.15 & 882.96 & 1,324 & - & 155.85 & $2,019.06$ \\
\hline $\begin{array}{l}\text { Skilled } \\
\text { nursing } \\
\text { facility }\end{array}$ & 7,252 & - & 152.54 & 567.78 & 16,752 & - & 352.36 & $1,311.57$ \\
\hline $\begin{array}{l}\text { Died in } \\
\text { hospital }\end{array}$ & 1,439 & - & 175.74 & 989.64 & 4,662 & - & 569.34 & $3,206.17$ \\
\hline Other $^{c}$ & 8,282 & - & 219.70 & 802.10 & 21,755 & - & 577.11 & $2,106.94$ \\
\hline \multicolumn{9}{|l|}{$\begin{array}{l}\text { Primary source of } \\
\text { payment }\end{array}$} \\
\hline Medicare & 32,085 & - & 220.41 & 913.00 & 63,421 & - & 435.68 & $1,804.68$ \\
\hline Medicaid & 7,445 & - & 97.42 & 560.04 & 37,547 & - & 491.32 & $2,824.44$ \\
\hline
\end{tabular}


Table 4 Demographics and Other Patient- and Facility-Specific Characteristics of Interest Among Adhesiolysis-Related Hospitalizations (i.e., DRG 150 or 151) in the US in 2005 (Continued)

\begin{tabular}{|c|c|c|c|c|c|c|c|c|}
\hline $\begin{array}{l}\text { Private } \\
\text { Insurance }\end{array}$ & 36,057 & - & 263.49 & 848.19 & 150,852 & - & $1,102.37$ & $3,548.56$ \\
\hline Other $^{d}$ & 5,853 & - & 181.10 & 731.63 & 18,280 & - & 565.60 & $2,285.01$ \\
\hline Missing & 91 & - & 186.24 & 528.76 & 145 & - & 296.76 & 842.53 \\
\hline \multicolumn{9}{|l|}{ Hospital region } \\
\hline Northeast & 16,376 & 29.95 & 211.20 & 857.55 & 55,070 & 100.71 & 710.24 & $2,883.80$ \\
\hline Midwest & 18,994 & 28.81 & 210.56 & 838.51 & 57,623 & 87.39 & 638.80 & $2,543.83$ \\
\hline South & 31,772 & 29.54 & 212.63 & 849.84 & 108,511 & 100.89 & 726.20 & $2,902.44$ \\
\hline West & 14,389 & 21.06 & 193.21 & 720.01 & 49,041 & 71.76 & 658.51 & $2,453.96$ \\
\hline \multicolumn{9}{|l|}{$\begin{array}{l}\text { Hospital location/ } \\
\text { teaching status }\end{array}$} \\
\hline Urban & 70,728 & - & 208.10 & 787.13 & 237,845 & - & 699.81 & $2,646.96$ \\
\hline Rural & 10,804 & - & 208.70 & $1,166.35$ & 32,399 & - & 625.86 & $3,497.65$ \\
\hline \multicolumn{9}{|l|}{ Hospital bed size ${ }^{e}$} \\
\hline Small & 10,532 & - & 218.05 & $1,001.92$ & 32,559 & - & 674.10 & $3,097.36$ \\
\hline Medium & 20,062 & - & 206.81 & 861.57 & 63,964 & - & 659.39 & $2,746.96$ \\
\hline Large & 50,938 & - & 206.78 & 779.80 & 173,721 & - & 705.23 & $2,659.47$ \\
\hline \multicolumn{9}{|l|}{$\begin{array}{l}\text { Hospital teaching } \\
\text { status }\end{array}$} \\
\hline Teaching & 32,737 & - & 200.09 & 698.61 & 108,747 & - & 664.68 & $2,320.66$ \\
\hline Nonteaching & 48,795 & - & 213.99 & 933.72 & 161,498 & - & 708.23 & $3,090.37$ \\
\hline \multicolumn{9}{|l|}{ Hospital control } \\
\hline $\begin{array}{l}\text { Government } \\
\text { or private, } \\
\text { collapsed }\end{array}$ & 47,163 & - & 207.20 & 775.62 & 155,489 & - & 683.12 & $2,557.11$ \\
\hline $\begin{array}{l}\text { Government, } \\
\text { nonfederal, } \\
\text { public }\end{array}$ & 5,150 & - & 197.77 & 978.84 & 16,048 & - & 616.29 & $3,050.19$ \\
\hline $\begin{array}{l}\text { Private, } \\
\text { nonprofit, } \\
\text { voluntary }\end{array}$ & 16,957 & - & 208.70 & 832.92 & 58,180 & - & 716.06 & $2,857.76$ \\
\hline $\begin{array}{l}\text { Private, } \\
\text { investor } \\
\text { owned }\end{array}$ & 8,419 & - & 205.72 & 867.45 & 30,627 & - & 748.36 & $3,155.64$ \\
\hline $\begin{array}{l}\text { Private, } \\
\text { collapsed }\end{array}$ & 3,843 & - & 243.13 & $1,286.57$ & 9,901 & - & 626.39 & $3,314.69$ \\
\hline
\end{tabular}

DRG = diagnosis-related group; HCUP = Healthcare Cost and Utilization Project; NHDS = National Hospital Discharge Survey; US = United States.

a Other category includes Hispanic, Asian/Pacific Islander, Native American, and "other" HCUP category (no further information provided in the data dictionary).

b Other category includes court and law enforcement, and routine, including "other" HCUP category (no further information provided in the data dictionary).

' Other category includes home health, against medical advice, and alive but destination unknown.

d Other category includes self-pay, no charge, and "other" HCUP category (no further information provided in the data dictionary).

e Hospital bed size is based upon facility-specific geographic location and teaching status. These allocations are from the NHDS classification grid. 
Table 5 Inpatient Care Attributable to Abdominal Adhesiolysis by Surgical Procedure in the US in 2005

\begin{tabular}{|c|c|c|c|c|c|c|}
\hline \multirow{2}{*}{$\frac{\text { Reason for Hospitalization }}{\text { (Diagnosis-Related Group) }}$} & \multicolumn{2}{|c|}{ Mean Length of Stay (Days) } & \multirow[b]{2}{*}{$\begin{array}{l}\text { AttributedLOS } \\
\text { (Days) }\end{array}$} & \multirow[b]{2}{*}{$\begin{array}{l}\text { Number of } \\
\text { Adhesiolysis-Related } \\
\text { Hospitalizations }\end{array}$} & \multirow[b]{2}{*}{$\begin{array}{l}\text { Attributed } \\
\text { Days of } \\
\text { Care }\end{array}$} & \multirow[b]{2}{*}{$\begin{array}{l}\text { Rate of Days } \\
\text { Due to } \\
\text { Adhesiolysis }\end{array}$} \\
\hline & Adhesiolysis & Nonadhesiolysis & & & & \\
\hline Adhesiolysis only (DRG 150, 151) & 7.76 & - & 7.76 & 81,532 & 632,688 & 7.76 \\
\hline \multicolumn{7}{|c|}{ Adhesiolysis as a Secondary Procedure } \\
\hline \multicolumn{7}{|c|}{ Digestive System } \\
\hline $\begin{array}{l}\text { DRG 148: Major small and large } \\
\text { bowel procedures with CC }\end{array}$ & 13.87 & 10.57 & 3.30 & 64,588 & 213,140 & 3.30 \\
\hline $\begin{array}{l}\text { DRG 149: Major small and large } \\
\text { bowel procedures without CC }\end{array}$ & 6.30 & 5.20 & 1.10 & 9,313 & 10,244 & 1.10 \\
\hline $\begin{array}{l}\text { DRG 154: Stomach, esophageal, } \\
\text { and duodenal procedures with } \\
\text { CC }\end{array}$ & 16.41 & 11.84 & 4.57 & 7,183 & 32,826 & 4.57 \\
\hline $\begin{array}{l}\text { DRG 468: Extensive OR } \\
\text { procedures unrelated to principal } \\
\text { diagnosis }\end{array}$ & 16.12 & 11.25 & 4.87 & 3,491 & 17,001 & 4.87 \\
\hline Digestive System Total & - & - & - & 84,575 & 273,212 & 3.23 \\
\hline \multicolumn{7}{|c|}{ Hepatobiliary System } \\
\hline $\begin{array}{l}\text { DRG 197: Total cholecystectomy } \\
\text { without CDE with CC }\end{array}$ & 8.66 & 8.10 & 0.56 & 4,698 & 2,631 & 0.56 \\
\hline $\begin{array}{l}\text { DRG 493: Laparoscopic } \\
\text { cholecystectomy without CDE } \\
\text { with CC }\end{array}$ & 5.99 & 5.21 & 0.78 & 9,568 & 7,463 & 0.78 \\
\hline $\begin{array}{l}\text { DRG 494: Laparoscopic } \\
\text { cholecystectomy without CDE } \\
\text { without CC }\end{array}$ & 2.70 & 2.46 & 0.24 & 6,811 & 1,635 & 0.24 \\
\hline Hepatobiliary System Total & - & - & - & 21,077 & 11,729 & 0.56 \\
\hline \multicolumn{7}{|c|}{ Female Reproductive System } \\
\hline $\begin{array}{l}\text { DRG 358: Uterine and adnexa } \\
\text { procedures for nonmalignancy } \\
\text { with CC }\end{array}$ & 3.90 & 3.00 & 0.90 & 38,263 & 34,437 & 0.90 \\
\hline $\begin{array}{l}\text { DRG 359: Uterine and adnexa } \\
\text { procedures for nonmalignancy } \\
\text { without CC }\end{array}$ & 2.46 & 2.14 & 0.32 & 81,543 & 26,094 & 0.32 \\
\hline $\begin{array}{l}\text { DRG 361: Laparoscopy and } \\
\text { incisional tubal interruption }\end{array}$ & 2.80 & 2.58 & 0.22 & 484 & 106 & 0.22 \\
\hline $\begin{array}{l}\text { DRG 365: Other female } \\
\text { reproductive system OR } \\
\text { procedures }\end{array}$ & 4.81 & 5.57 & -0.76 & 4,779 & $-3,632$ & -0.76 \\
\hline $\begin{array}{l}\text { Female Reproductive System } \\
\text { Total }\end{array}$ & - & - & - & 125,069 & 57,005 & 0.46 \\
\hline \multicolumn{7}{|c|}{ Pregnancy, C-Section } \\
\hline $\begin{array}{l}\text { DRG 370: Cesarean section with } \\
\text { CC }\end{array}$ & 4.30 & 4.45 & -0.15 & 9,901 & $-1,485$ & -0.15 \\
\hline $\begin{array}{l}\text { DRG 371: Cesarean section } \\
\text { without CC }\end{array}$ & 3.12 & 3.37 & -0.25 & 26,011 & $-6,503$ & -0.25 \\
\hline DRG 378: Ectopic pregnancy & 2.16 & 1.97 & 0.19 & 3,612 & 686 & 0.19 \\
\hline Pregnancy, C-section Total & - & - & - & 39,524 & $-7,302$ & -0.18 \\
\hline $\begin{array}{l}\text { Total, Adhesiolysis as a secondary } \\
\text { procedure }\end{array}$ & - & - & - & 270,245 & 334,644 & 1.24 \\
\hline $\begin{array}{l}\text { Total, all adhesiolysis-related } \\
\text { procedures }\end{array}$ & - & - & - & 351,777 & 967,332 & 2.75 \\
\hline
\end{tabular}


Table 6 Inpatient Expenditures Attributable to Abdominal Adhesiolysis in the US in 2005

\begin{tabular}{|c|c|c|}
\hline Expenditure & Attributed to Adhesiolysis & Total in Millions (2007 \$) \\
\hline \multicolumn{3}{|l|}{ By type of procedure } \\
\hline \multicolumn{3}{|c|}{ Adhesiolysis as primary procedure } \\
\hline Total days of care & 632,688 & $\$ 1,277$ \\
\hline Surgical procedures & 81,532 & $\$ 68$ \\
\hline Subtotal & - & $\$ 1,345$ \\
\hline \multicolumn{3}{|c|}{ Adhesiolysis as secondary procedure } \\
\hline Total days of care & 334,644 & $\$ 675$ \\
\hline Surgical procedures & 270,245 & $\$ 227$ \\
\hline Subtotal & - & $\$ 902$ \\
\hline \multicolumn{3}{|c|}{ Cost stratification of secondary adhesiolysis, by body system } \\
\hline \multicolumn{3}{|l|}{ Digestive system } \\
\hline Total days of care & 273,212 & $\$ 551$ \\
\hline Surgical procedures & 84,575 & $\$ 71$ \\
\hline Subtotal & - & $\$ 622$ \\
\hline \multicolumn{3}{|c|}{ Hepatobiliary system and pancreas } \\
\hline Total days of care & 11,729 & $\$ 24$ \\
\hline Surgical procedures & 21,077 & $\$ 18$ \\
\hline Subtotal & - & $\$ 41$ \\
\hline \multicolumn{3}{|c|}{ Female reproductive system } \\
\hline Total days of care & 57,005 & $\$ 115$ \\
\hline Surgical procedures & 125,069 & $\$ 105$ \\
\hline Subtotal & - & $\$ 220$ \\
\hline \multicolumn{3}{|l|}{ Pregnancy, C-sections } \\
\hline Total days of care & $-7,302$ & $-\$ 15$ \\
\hline Surgical procedures & 39,524 & $\$ 33$ \\
\hline Subtotal & - & $\$ 18$ \\
\hline Total expenditures & - & $\$ 2,247$ \\
\hline
\end{tabular}

US = United States.

procedure has not been show to reduce the incidence of adhesion-related readmissions [16].

This study is subject to potential limitations consistent with retrospective database studies. Conditions and events of interest were identified by diagnosis codes. Previous research has suggested that the condition may be underreported [17]. This may mean that the actual cost of adhesiolysis-related disease is greater than the estimate provided by our study. The database used for this study was not specifically designed to assess inpatient burden. Like all administrative billing databases, the data contained in the HCUP NIS are dependent upon the quality of coding, which may be influenced by reimbursement incentives. However, we do not feel it likely that such incentives greatly affected our results since the majority of overall adhesiolysis costs were a part of secondary adhesiolysis procedures and not the more costly primary adhesiolysis. Moreover, even if such incentives exist and are reflected in the data used for this study, these data are indicative of real world practice. Additionally, with such a large sample, the effect of any coding errors or anomalies would likely be minimized.
Furthermore, due to the nature of the database, detailed clinical characteristics could not be ascertained; therefore, the results could not be adjusted for disease severity or other clinical parameters. However, it is unlikely that these factors would have had a large impact on the results, as this study focused on those patients receiving inpatient care. Additionally, since the database contains US data only, the results may not be generalizable to other populations outside of the US. Lastly, because the focus of this study was on direct cost measures, the results do not account for productivity loss for the patient or caregiver and potential future societal contributions that may be lost due to death resulting from or related to adhesiolysis. Because we examined only the direct health care costs associated with inpatient adhesiolysis, we have not examined any adhesiolysis-related surgeries performed at other sites of care, such as ambulatory surgical centers. Further, our study does not capture direct costs relating to but occurring before or after surgery, including pain medications, cost of work-up visits, and procedures related to diagnosis. Similarly, patient work-ups and diagnostic laparoscopic procedures that may have occurred at 
separate visits and prior to the adhesiolysis surgery were not captured if specific DRG codes were not listed for those hospitalizations $[6,7,9]$. Hence, this study's estimates of costs are likely to be conservative.

\section{Conclusions}

Adhesions remain an important surgical problem, and hospitalization for adhesiolysis leads to a high direct cost burden in the US. Despite a trend of decreasing LOS for adhesiolysis-related hospitalizations from 2001 to 2005, adhesiolysis-related costs continue to rise even while the overall rate of adhesiolysis procedures remains constant. Consistent with previous research, the distribution of inpatient care and costs across the diagnostic categories remained steady from 2001 to 2005, with only a slight increase in primary adhesiolysis procedures over time. From 2001 to 2005, hospitalizations for adhesiolysis related to the digestive system and to the female reproductive tract had the largest number of inpatient days and accounted for the majority of costs related to secondary adhesiolysis procedures.

Adhesiolysis remains a substantial economic burden to the US health care system, which should be of interest to providers and commercial and government payers. Further research incorporating detailed clinical data and indirect costs would aid in a greater understanding of the overall burden of adhesiolysis.

\section{Funding}

This study and the preparation of this manuscript were funded by Ethicon, Inc. The authors acknowledge that Ethicon, Inc. is the maker of GYNECARE INTERCEED, a product that is marketed to prevent pelvic adhesions.

\section{Acknowledgements}

Portions of the study data presented in this paper were previously presented as a podium presentation at the VIII ${ }^{\text {th }}$ PAX Meeting; ClermontFerrand, France; September 18-20, 2008, as well as a poster presentation at the $57^{\text {th }}$ Annual Clinical Meeting of the American College of Obstetricians and Gynecologists; Chicago, Illinois; May 2-6, 2009.

The authors wish to thank Ms. Gail Zona of RTI Health Solutions and Ms. Heidi Waters of Ethicon, Inc., for assistance with preparing this manuscript.

\section{Author details}

${ }^{1}$ Shire Pharmaceuticals, Wayne, PA 19087 USA. ${ }^{2}$ RTI Health Solutions, 200 Park Offices, Research Triangle Park, NC 27709 USA. ${ }^{3}$ The Christie NHS Foundation Trust, Manchester, M20 4BX, UK. ${ }^{4}$ Texas Health Care, Fort Worth, TX 76109 USA.

\section{Authors' contributions}

VS was responsible for developing the study design, interpreting the analysis results, and drafting the manuscript text; he is the primary author of this manuscript. BB, SDC, and KLD were responsible for the acquisition, management, interpretation, and analysis of all study data. BB, SDC, and KLD also assisted with developing the study design, interpreting the analysis results, and drafting the manuscript. AJ and MW contributed clinical expertise and guidance and assisted in interpreting the analysis results and drafting the manuscript text.
All authors confirm that they have read the journal's position on issues involved in ethical publication and affirm that this research report is consistent with those guidelines. Finally, all authors have read and approved the final manuscript.

\section{Competing interests}

VS was an employee of Ethicon, Inc. at the time that this manuscript was prepared; he is currently an employee of Shire Pharmaceuticals. BB, SDC, and KLD are employees of RTI Health Solutions, the research organization contracted by Ethicon to conduct this study. AJ is an employee of Texas Healthcare; MW is an employee of Christie NHS Foundation Trust.

Received: 5 January 2011 Accepted: 9 June 2011 Published: 9 June 2011

\section{References}

1. Beck DE: Understanding abdominal adhesions. Ostomy Q 2001, 38(2):50-51.

2. Ray NF, Denton WG, Thamer M, Henderson SC, Perry S: Abdominal adhesiolysis: inpatient care and expenditures in the United States in 1994. J Am Coll Surg 1998, 186(1):1-9.

3. Menzies D, Parker M, Hoare R, Knight A: Small bowel obstruction due to postoperative adhesions: treatment patterns and associated costs in 110 hospital admissions. Ann R Coll Surg Engl 2001, 83:40-46.

4. diZerega GS, Tulandi T: Prevention of intra-abdominal adhesions in gynaecological surgery. Reprod Biomed Online 2008, 17:303-306.

5. Tingstedt B, Isaksson J, Andersson R: Long-term follow-up and costs analysis following surgery for small bowel obstruction caused by intraabdominal adhesions. Br J Surg 2007, 94:743-748.

6. Ellis H, Moran BJ, Thompson JN, Parker MC, Wilson MS, Menzies D, McGuire A, Lower AM, Hawthorn RJ, O'Brien F, Buchan S, Crowe AM: Adhesion-related hospital readmissions after abdominal and pelvic surgery: a retrospective cohort study. Lancet 1999, 353:1476-1480.

7. Parker MC, Ellis H, Moran BJ, Thompson JN, Wilson MS, Menzies D, McGuire A, Lower AM, Hawthorn RJ, O'Briena F, Buchan S, Crowe AM: Postoperative adhesions: ten-year follow-up of 12,584 patients undergoing lower abdominal surgery. Dis Colon Rectum 2001, 44:822-829.

8. Lower AM, Hawthorn RJ, Ellis H, O'Brien F, Buchan S, Crowe AM: The impact of adhesions on hospital readmissions over ten years after 8489 open gynaecological operations: an assessment from the Surgical and Clinical Adhesions Research Study. Br J Obstet Gynaecol 2000, 107:855-862.

9. Meagher AP, Moller C, Hoffmann DC: Non-operative treatment of small bowel obstruction following appendectomy or operation on the ovary or tube. Br J Surg 1993, 80:1310-1311.

10. Ray NF, Larsen JW, Stillman RJ, Jacobs RJ: Economic impact of hospitalizations for lower abdominal adhesiolysis in the United States in 1988. Surg Gynecol Obstet 1993, 176:271-276.

11. HCUP Nationwide Inpatient Sample. Healthcare Cost and Utilization Project (HCUP). [http://www.hcup-us.ahrq.gov/nisoverview.jsp].

12. Steiner C, Elixhauser A, Schnaier J: The Healthcare Cost and Utilization Project: an overview. Eff Clin Pract 2002, 5(3):143-151.

13. US Bureau of Labor Statistics. Consumer Price Index for medical services. [http://data.bls.gov/PDQ/outside.jsp?survey=cu].

14. SAS Institute Inc: SAS 9.1.3. Cary, NC: SAS Institute Inc; 2003.

15. Research Triangle Institute: SUDAAN (Release 9.0.1). Research Triangle Park, NC: Research Triangle Institute; 2005.

16. Gutt CN, Oniu T, Schemmer P, Mehrabi A, Büchler MW: Fewer adhesions induced by laparoscopic surgery? Surg Endosc 2004, 18(6):898-906.

17. Parker MC, Wilson MS, Menzies D, Sunderland G, Clark DN, Knight AD, Crowe AM, Surgical and Clinical Adhesions Research (SCAR) Group: The SCAR-3 study: 5-year adhesion-related readmission risk following lower abdominal surgical procedures. Colorectal Dis 2005, 7:551-558.

Pre-publication history

The pre-publication history for this paper can be accessed here: http://www.biomedcentral.com/1471-2482/11/13/prepub

doi:10.1186/1471-2482-11-13

Cite this article as: Sikirica et al:: The inpatient burden of abdominal and gynecological adhesiolysis in the US. BMC Surgery 2011 11:13. 